revista ANTHROPOLÓGICAS

Ano 22, 29(2):114-141, 2018

\title{
A Multiplicidade do Cuidado na Experiência da Deficiência
}

\author{
Helena Moura Fietz \\ Anahi Guedes de Mello ${ }^{b}$
}

A categoria cuidado é central na teoria feminista da deficiência. Ainda assim, enquanto um termo êmico e analítico, o cuidado tem sido objeto de controvérsias entre teóricas e ativistas do campo da deficiência. Pretendemos traçar a trajetória desta categoria dentro do movimento social e das teorias que embasam o modelo social da deficiência. A abordagem parte de pesquisas realizadas em Porto Alegre e Belo Horizonte, Brasil, junto a mães/cuidadoras de adultos com deficiência cognitiva e a mulheres com deficiência física com histórico de violências. Problematizaremos três aproximações comumente acionadas no cotidiano de nossas(os) interlocutoras(es) - o cuidado como 'superproteção', como 'educar' e como 'violência' - por entendermos que elas proporcionam uma reflexão teórica em torno da polarização entre os conceitos 'cuidado', 'autonomia' e 'independência'. Refletiremos o cuidado não apenas enquanto uma prática social e emocional e uma categoria moral sob a qual incide múltiplas valorações, mas também uma 'entrada etnográfica'.

Cuidado, Deficiência, Autonomia, Independência.

A intersecção entre cuidado e deficiência vem sendo tema de inúmeras reflexões ao longo dos anos (Kittay 1999; Diniz 2007; Krö-

a Doutoranda no Programa de Pós Graduação em Antropologia (UFRGS). Email: helenafietz@gmail.com.

b Doutoranda no Programa de Pós-graduação em Antropologia social (UFSC). Email: anahigm75@gmail.com. 
ger 2009; Guimarães 2010; Mello \& Nuernberg 2012). Enquanto categoria o cuidado é controverso, porquanto objeto de disputas teóricas e políticas entre os movimentos e estudos feministas e os movimentos e estudos da deficiência. De um lado, é rechaçado por ativistas da deficiência que o compreendem como uma categoria reificadora de estigmas, incapacidade e infantilização da pessoa com deficiência (Morris 1997; Hughes et al. 2017). De outro lado, desde a década de 1980, teorias sobre o cuidado (Hirata \& Guimarães 2012) vem sendo desenvolvidas por pesquisadoras feministas de distintos campos acadêmicos para destacar, entre outras coisas, a importância de se reconhecer o valor do trabalho do cuidado - comumente realizado por mulheres - e de se questionar os ideais de autonomia e independência enquanto universais e absolutos (Held 1993; Tronto 1993; Kittay 1999; Reindal 1999; Diniz 2007; Hirata \& Guimarães 2012).

No presente trabalho, focaremos na segunda dimensão da categoria a fim de demonstrar como a polissemia desse termo o torna uma potente categoria analítica para reflexões acerca da deficiência. A partir de nossas experiências de pesquisa de campo junto a grupos de mulheres que experienciam a deficiência em seu cotidiano - mães de adultos com deficiência cognitiva e mulheres com deficiência física com histórico ou em situação de violência - apresentaremos algumas possibilidades de análise sobre o cuidado. Ao fomentar esse debate, nosso objetivo é demonstrar uma multiplicidade do cuidado na experiência da deficiência, em que a 'multiplicidade' parte do sentido proposto por Annemarie Mol (2002 e 2008a). Neste caso, pensar o cuidado como uma prática que se constrói e é performada em 'múltiplas versões', todas elas interagindo e coexistindo entre si (Mol 2008b; Fietz 2016; Fonseca \& Fietz 2018). Nesse sentido, não se trata de atribuir diferentes significados a uma mesma categoria, mas de mostrar como a realidade ontológica do cuidado é múltipla. Para essa autora, a "ontologia não precede práticas de conhecimento, mas é 'feita' (performada ou atuada, instituída, implementada, ocasionada) nessas 
práticas. E porque há muitas práticas, há muitas ontologias." (Martin, Spink \& Pereira 2018:301).

Nossa abordagem também vai ao encontro de estudiosas feministas do cuidado, em especial a filósofa Eva Federer Kittay, para quem pensar a deficiência a partir de uma ética do cuidado é central para que os ideais de autonomia e independência sejam questionados. Para além de pensar o gênero e deficiência como parâmetros para uma 'economia do cuidado', a autora concebe o cuidado como uma questão de justiça social, por ser um princípio ético e moral da própria condição humana, com base na premissa da interdependência que rege as relações humanas ${ }^{1}$, desde o nascimento até a morte ${ }^{2}$. Nesse sentido, a autora compreende que o estigma decorre não da necessidade de receber cuidados, mas sim da noção de independência enquanto normatividade (Kittay 2007). Por isso, nossa proposta passa por pensar criticamente sobre esta oposição que comumente se dá entre as noções de cuidado e as de autonomia e independência.

Não pretendemos aprofundar neste texto as tantas teorias já desenvolvidas acerca das noções de autonomia e independência. Entretanto, é importante apontar que para boa parte do movimento social da deficiência a independência seria a faculdade de tomar as próprias decisões, de fazer escolhas, enquanto a autonomia seria a possibilidade de controlar o próprio corpo em torno do ambiente mais próximo 3 (Mello 2010). Nessa visão, a provisão do cuidado - ou assistência - seria algo bastante instrumental, uma interação entre 'pessoas independentes' para que aquele cuja autonomia seja restrita, atinja seu fim. Ocorre que, como aponta Kittay (2011), nas relações de cuidado as partes sempre coexistem, estão intimamente ligadas e suas ações têm influências diretas uns sobre outros. Nesse sentido, não se trata de não reconhecer a importância de que as pessoas participem de decisões, mas sim de chamar a atenção para os perigos de se enaltecer a ideia de escolha enquanto um 'bem maior', apagando, assim, as inúmeras camadas que levam a situações onde estas decisões são tomadas. 
Cientes do quão polissêmico o termo cuidado é e dos riscos imanentes de que um conceito que pode vir a ser utilizado para muitas situações acabe perdendo seu potencial analítico, argumentamos que é justamente nesta multiplicidade que reside a potência de se pensar a experiência da deficiência também a partir das relações de cuidado, por meio das práticas que a conforma e que são por ela conformadas. Sem a pretensão de apresentar um conceito fechado, optamos por, neste momento, chamar a atenção para o cuidado enquanto um trabalho (labour) e também uma atitude. Ou seja, ele é ao mesmo tempo o trabalho (work) de garantir que aqueles que necessitem recebam o que é necessário e a atitude de interessar-se pelo bem-estar do outro e de si (Kittay 2007). Aqui o cuidado é pensado não só enquanto 'práticas' que dele advém, mas também enquanto 'virtudes' a ele atreladas. Nesse sentido, trata-se de uma prática que é permeada por moralidades.

Chamamos a atenção, no entanto, para os paradoxos do cuidado, a fim de evidenciar como a aproximação entre cuidado e deficiência pode ocorrer na prática. Estamos de acordo com a ideia de que toda pessoa compartilha a necessidade de ser cuidada da mesma forma que se constitui como cuidadora em vários momentos da vida. Ocorre que o cuidado constitui-se de várias formas, assumindo muitas versões e, por conseguinte, pode incorrer em efeitos diversos tanto para quem cuida quanto para quem é cuidado. Neste trabalho apresentaremos três versões do cuidado que encontramos em nossas pesquisas de campo, respectivamente em Porto Alegre, Belo Horizonte e na internet, via grupo de discussão por e-mail, no período de 2012 até 20184: 'superproteção', 'educação' e 'violência'. Falaremos, portanto, ao mesmo tempo de efeitos, práticas e acusações morais que permeiam ações e discursos baseados no cuidado. Por fim, discorremos sobre as implicações de se pensar a deficiência também a partir do cuidado e pontuamos como estes paradoxos decorrem não das práticas em si, mas de presunções de que pessoas com deficiência sempre necessitam de cuidado, sem muitas vezes atentar-se para suas necessidades e desejos, 
o que pode acabar por estigmatizar a pessoa que recebe o cuidado ao mesmo tempo em que sobrecarrega aquelas que o provêm.

\section{O cuidado como superproteção}

Uma das críticas mais fortes ao termo cuidado advém de ser este uma categoria infantilizadora, onde a pessoa com deficiência é sempre tida como uma pessoa cuja autonomia e independência são cerceadas. Nesta perspectiva, as práticas de cuidado seriam sempre permeadas por concepções de inferioridade àquela que as recebe, criando uma desigualdade inerente a estas relações que podem desencadear opressão e supressão de potencialidades e de agência (Morris 1997), sendo uma visão muitas vezes associada ao cuidado familiar, em especial o materno. Nesse sentido, a linha que separa o 'bom cuidado' da acusação de 'superproteção' é tênue e comumente borrada.

Este ponto é particularmente marcado nas interações de campo junto a um grupo de mães de adultos com deficiência cognitiva ${ }^{5}$ em uma associação da cidade de Porto Alegre, que promove atividades como judô, arteterapia, musicoterapia, capoeira e esportes para adultos com deficiência. Há quase vinte anos, a organização tem como principais objetivos 'promover a autonomia e independência das pessoas com deficiência', 'apoiar as famílias' e 'trabalhar em prol de uma sociedade mais inclusiva e solidária'. Não por acaso, os profissionais que ali trabalham - das áreas da assistência social, educação física e contabilidade - são muito próximos das famílias que a frequentam. Desde julho de 2017 é feito o trabalho de campo no local, participando de reuniões, atividades e interações diversas junto às mães que ali aguardam seus filhos realizarem as atividades oferecidas. As reflexões aqui apresentadas advém da observação da interação dessas mulheres com profissionais do campo da saúde e da assistência social, através de uma série de palestras promovidas em 2018.

Em uma dessas ocasiões, Rafael $^{6}$, professor e figura importante dentro da organização, destacou que o trabalho dos educadores passa 
por incentivar a autonomia e independência das pessoas com deficiência, sendo isso algo que exige de todos que trabalham com ele. Ao se dirigir diretamente para as mães, passou a narrar atitudes que presenciou ao longo dos mais de vinte anos em que trabalha com pessoas com deficiência cognitiva:

"Por exemplo, depois da aula de natação, se a pessoa sabe colocar a meia sozinha, deixa colocar a meia sozinha. Agora às vezes vem a mãe e me diz: 'Ah não, não pode deixar ela colocar a meia porque ela não sabe!'. E eu só digo: 'Pode até não saber, mas olha ali: ela colocou!' E às vezes as mães reclamam que colocou a meia virado. Poxa, tudo bem, estava virada, mas colocou a meia sozinha. Então a gente tem que estimular que coloque a meia sozinho, que faça o máximo que conseguir. Eu quando vou contratar alguém pra minha equipe eu procuro duas coisas: que ame o que faz e que não tenha frescura. Porque pra fazer o que a gente faz, tem que gostar, tem que amar, tem que querer. E tem que ter o perfil de puxar pra autonomia, de buscar a independência. E ao mesmo tempo tem que estar pronto pra, se precisar, ir no banheiro com a pessoa e ajudar a limpar."

A fala de Rafael traduzia aquilo que considera imprescindível para trabalhar com pessoas com deficiência: equacionar a busca por autonomia e, ao mesmo, estar pronto para dar o apoio e suporte necessários. Seguiu destacando o quão importante é que as mães, tias, avós, madrinhas, irmãs e quem estivesse ali ou fosse responsável pela pessoa que deixasse ela fazer as coisas por si só, que permitisse que fossem aos passeios, aos acampamentos e em outras atividades voltadas para as pessoas com deficiência. Olhando diretamente para algumas mães, Rafael passou a dar exemplos de atitudes que, para ele, dificultavam esta busca por autonomia, como a experiência que teve com uma mãe que lhe reclamou apenas porque a filha colocou a calça virada após um treino de natação ou aquelas que não permitiam que participassem dos acampamentos por medo de que algo lhes acontecesse na semana. Acabou sua fala contando da viagem que fizeram no final do ano de 2016, quando foram à cidade de Canela passar o dia. Naquela ocasião, foram a uma pizzaria e o dono, na tentativa de auxiliá-los, 
informou que poderia disponibilizar um garçom para cada um dos jovens, ao que Rafael teria respondido:

"Cara, não é isso que a gente quer. Deixa cada um comer sozinho. A gente ajuda no que precisar, mas cada um vai comer como conseguir, se sujar tudo, se fizer bagunça, paciência. $\mathrm{O}$ que a gente quer não é a inclusão nossa no mundo, o que a gente quer é o contrário, é que o mundo esteja preparado para a gente. Não o contrário”.

A fala de Rafael ilustra algumas questões centrais para o nosso argumento, uma vez que para ele o grande impeditivo para que as pessoas com deficiência atinjam essa autonomia é a superproteção materna, o excesso de zelo, de cuidado. No entanto, o fato do mundo não aceitar que algumas pessoas irão comer do jeito que conseguirem e se sujar mais do que talvez seja o esperado nessas situações também seria um impeditivo para que elas possam realizar essas atividades sozinhas. Quando Rafael diz que "não quer a inclusão”, mas sim "um mundo preparado para a gente", ele deixa evidente que permitir que as pessoas com deficiência cognitiva realizem sozinhas as tarefas cotidianas básicas implica aceitar que nem todas são capazes de executar o ato de comer do mesmo modo que as demais. Por isso, romper ou mesmo subverter a 'normalidade' como padrão de referência também está presente em seu discurso.

Apesar de Rafael reconhecer em sua fala o quão pouco preparado o mundo está para lidar com a diversidade corporal/funcional, sua fala dirigida às mães salienta o aspecto que considera mais problemático da relação de cuidado entre essas mães e seus filhos e filhas com deficiência: a superproteção. São as mães, afinal, quem mimam os filhos e impedem que eles cresçam e atinjam habilidades e potencializem suas capacidades. Ao mesmo tempo, o tipo de cuidado empregado por estas mães são aqueles que ministraram durante toda a vida de seus filhos, durante as quais foram sempre as principais responsáveis, contando com quase nenhum suporte estatal ou até mesmo de uma rede familiar mais presente. Muitas vezes aquilo que se enxerga como um 'bom cuidado' pode ser percebido como um 'mau cuidado', quan- 
do passa a sufocar os ímpetos de independência e direito do outro ao erro (Molinier 2012).

Esta perspectiva está ligada à noção de dependência tão exarcebada que acaba por subsumir a individualidade do outro e que foi abordada em uma palestra ministrada por uma psicóloga e uma assistente social. Naquela ocasião, a plateia era composta por cerca de trinta familiares de pessoas com deficiência cognitiva, sendo que destes apenas dois eram homens. Elas iniciaram sua fala destacando "a necessidade de olhar também para si, de desgrudar um pouco, de conseguir se ver separado do filho". Já naquela primeira frase, as mães trocaram olhares de cumplicidade, talvez por estarem acostumadas a tantas intervenções neste sentido. A psicóloga então reiterou sua posição e disse com uma voz mais firme:

"A gente quer falar do cuidado de si. Porque como a gente vê casos de mães e pais que chegam pra nós e nos dizem que fazem isso 24 horas por dia, que a vida é toda voltada para o cuidado de quem precisa e que não sobra tempo para elas. Porque a gente tá falando de um cuidado que é permanente, né? Não é aquele cuidado de mãe de criar para o mundo, que depois de um tempo vai ir embora, é um cuidado que precisa de mais atenção, de mais envolvimento, um cuidado que nem sempre a pessoa vai ter aquela autonomia que a gente espera."

Uma das mulheres ali presentes, mãe de um jovem de vinte anos, pediu a palavra para contar sua experiência:

"Quando a gente centraliza demais tudo e fica muito vivendo só pra isso a gente começa a ficar prisioneira. A gente cria uma gaiola de proteção pra gente e para ele [o filho]. E essa gaiola começa a nos aprisionar e aprisiona a ele também, porque a gente acaba não deixando a pessoa fazer aquilo que talvez até conseguisse fazer, mas não consegue. É uma coisa que é importante."

A psicóloga adorou a intervenção e completou-a olhando diretamente para a mãe, afirmando que "a gente tem que se permitir ser. Ser a gente. Porque um mais um tem que somar dois, se o resultado for um é porque um dos dois não está vivendo." Destacou que não 
era a intenção de ninguém ali ensinar as mães como criar seus filhos, mas sim que aqueles momentos proporcionassem uma reflexão sobre o que era possível, o que se poderia mudar para deixar a vida de todos um pouco mais fácil.

Diante dessas falas, Camila, mãe de um jovem de dezoito anos, disse entre risos e gestos bem marcados que na verdade ninguém sabe muito bem o que fazer, já que não há um manual de como ser mãe. Olhando para as outras mulheres que ali estavam, afirmou que "as mães dos ditos normais também superprotegem, também fazem as coisas por eles, também colocam essa gaiola, né? Só que daí chega uma hora que eles saem, mas com a gente é diferente porque eles nunca saem.” Mais uma vez, a fala foi recebida com palavras e gestos de concordância das outras mães. Mari, mãe de uma mulher com trinta anos, pensou a respeito daquela consideração e afirmou: "A gente paparica mesmo. A gente protege muito, acha que está protegendo e acaba estragando." Ao que Alda, cujo filho tem apenas dez anos, afirmou que podia até ser verdade que elas protegiam demais, mas que não podiam esquecer que com seus filhos as coisas eram um pouco diferentes: "A gente tenta proteger mais, mas acaba estragando também, mimando muito, fazendo muita coisa por eles que eles poderiam fazer sozinhos."

O trabalho do cuidado é comumente desvalorizado e invisibilizado (Molinier 2012; Faur 2014; Debert \& Pulhez 2017), em especial em se tratando de cuidado materno. Conforme argumenta Ruddick (1989), faz parte da maternagem preparar o(a) filho(a) para ser aceito no mundo do qual faz parte, cabendo às mães também garantir que consigam realizar as atividades da vida cotidiana por si sós, bem como tomar suas próprias decisões, o que é corroborado pelas falas de profissionais como Rafael e a psicóloga. No entanto, como aponta, Kittay (2010), para as mães de pessoas com deficiência - e em especial aquelas que são 'mais dependentes' - há ainda uma tarefa igualmente importante: preparar o mundo para o(a) filho(a). Uma tarefa nem sempre fácil, mas com a qual estas mulheres lidam cotidianamente 
ao enfrentarem olhares de reprovação no transporte público, ao não serem convidadas para festas familiares, ou ao preocuparem-se quando os filhos sofrem qualquer forma de violência ou discriminação por parte daqueles que não compreendem sua condição. De fato, a linha entre o cuidado e a superproteção é borrada, tênue, porquanto traçada na prática cotidiana destas relações. Conforme já dito, é igualmente comum que muitas mães sejam acusadas de negligenciarem o cuidado a seus filhos e filhas caso algo venha a lhes acontecer. Interpeladas pela busca por maior autonomia e independência, elas se veem mais uma vez acusadas de não estarem fazendo o melhor ou o suficiente para o(a) filho(a), de "estar estragando-o(a)". Encontrar o equilíbrio entre a proteção e a superproteção é um desafio diário para essas mulheres dessas narrativas.

Ainda, cabe uma última observação: embora seja muito importante dissociar o cuidado da armadilha do gênero (Tronto 1993; Kittay 1999; Morris 2001; Molinier 2012; Mello \& Nuernberg, 2012), enquanto atividades pelas quais necessidades específicas são atendidas dentro de um contexto de relações de dependência, o trabalho do cuidado é realizado na maior parte por mulheres. Desse modo, o cuidado como narrativa ética não pode, do ponto de vista metodológico, prescindir da perspectiva de gênero (Molinier 2012: 37) em qualquer análise que o envolva.

\section{O cuidado como educação ou entre cuidar e educar}

Nesta situação etnográfica, acompanhou-se por e-mail as reações de educadoras e pais e mães de crianças com deficiência intelectual à matéria intitulada 'Justiça decide que aluna com síndrome de Down deve ter professor exclusivo'? Destacamos três depoimentos que mobilizam uma economia moral com base nos valores que amparam a politização do cuidado na educação de pessoas com deficiência:

"Nas escolas públicas, dados os índices de alfabetização e outros mais, cada aluno deveria ter um professor privativo então, independente de deficiência. Provavelmente outras decisões assim já foram 
tomadas nos tribunais, mas quem são os beneficiários de decisões como essa? Justamente as escolas e seus 'pensadores' pedagógicos, que assim legitimam-se a excluir dentro da escola. Sem direito a brincar no pátio. Isso é deprimente, me desculpem. Estou contra isso diametralmente" (Pai, depoimento 1).

"Não sou contra, obviamente, uma sala de alunos mais novos ter duas professoras ao mesmo tempo, para acompanharem TODOS OS ALUNOS. Mas sou absolutamente contra o professor acompanhante de aluno com deficiência. Isso só torna o aluno diferente e o afasta ainda mais dos colegas. Sempre dei aulas sozinha para alunos com deficiência em classes regulares e me virei mais ou menos bem. Ano passado veio a novidade do professor acompanhante (comemorada pela escola e anunciada pelo governo municipal como um passo a favor da inclusão), mas eu não concordava de jeito nenhum com a presença de uma professora exclusiva para meu aluno com autismo, no $9^{\circ}$ ano. Apesar dos meus protestos, ela foi até o fim, mas acho que isso só atrapalhou o aluno e toda a turma" (Educadora, depoimento 2).

"Impossível comemorar. Um professor exclusivo configura profunda discriminação. Estamos vendo uma avalanche de pedidos, por parte dos pais, e de exigências, por parte das escolas (especialmente particulares), para que alunos com deficiência tenham cuidadores/ professores exclusivos em sala de aula. Profissionais que não são contratados de acordo com as necessidades reais das crianças para questões de locomoção, alimentação, higiene e comunicação. São pessoas contratadas pelo simples fato de a criança ter deficiência. Um recado dado à escola e aos colegas de turma do aluno: esta pessoa, só por ter deficiência, não tem autonomia. $\mathrm{O}$ resultado nefasto é mais discriminação e o atraso no desenvolvimento dessas crianças. [...] No fim, vemos uma prática pedagógica excludente, em que o aluno fica em um canto, fazendo atividades diferentes das dos colegas, com o 'apoio' eterno. [...] Esse contexto nos mostra que não estamos conseguindo transformar a cultura do 'incapaz', do 'coitadinho', na escola (particular, principalmente!), e junto a atores estratégicos, como promotores e juízes. Isso pode e deve balizar nossos próximos passos. A judicialização de questões pedagógicas tem causado retrocessos e/ou atrasos no processo de implementação da Política de Educação Inclusiva. Vemos promotores pleiteando vagas em escolas ou classes especiais. Vemos decisões de juízes como esta. Sem compreender o que estamos construindo, os atores da justiça, ao invés de serem parceiros importantes, tornamse promotores de exclusão" (Educadora, depoimento 3). 
De modo geral, há dois conflitos morais envolvendo a presença ou demanda por um 'professor auxiliar', de formação em 'educação especial', em sala de aula visando atender pessoas com deficiência que têm 'necessidades específicas': o primeiro diz respeito à posição dos pais e mães de crianças com deficiência quanto à presença do/ da professor/a auxiliar em sala de aula, posto que há aqueles(as) que são contra (por acreditarem que isso geraria uma dependência negativa da criança com deficiência pela sua cuidadora, não contribuindo para a sua efetiva inclusão em sala de aula) e há aqueles(as) que são a favor (por acreditarem que isso promoveria maior autonomia e independência e, consequentemente, promoveria a inclusão de seu(sua) filho(a) com deficiência na sala de aula). Percebe-se que essa polarização traz certos impasses, posto que alguns pais e mães de crianças com deficiência e operadores/as do Direito generalizam a medida da exigência de um professor auxiliar como aplicável a todos os casos de crianças e adolescentes com deficiência

Segundo a coordenadora geral de Educação Inclusiva da Secretaria Municipal de Educação (Semed) de um município localizado na região sul do país, a solicitação por um professor auxiliar não se aplica a todos os casos, nem mesmo às pessoas com síndrome de Down. Em outras palavras, a necessidade de um professor auxiliar está atrelada às especificidades de cada aluno(a) com deficiência, sobretudo, por tipo de deficiência. Para ela, não há como contratar um professor auxiliar para cada aluno(a) com deficiência. Por outro lado, há professoras que questionam a contratação ou o porquê da presença de um professor auxiliar para atender apenas um(a) único(a) aluno(a) com deficiência em sala de aula, como se isso fosse desperdício de tempo e dinheiro. Essa lógica também se aplica aos discursos que questionam as medidas de 'adaptações razoáveis' para atender apenas um pequeno número de alunos(as) com deficiência (intérpretes de Língua Brasileira de Sinais para alguns(mas) alunos(as) surdos(as), rampas para alguns(mas) alunos(as) cadeirantes, etc.), "como se isso fosse um favor e não um direito". Há também os discursos dos profissionais da educação e da 
saúde se negando a prestar o papel de 'cuidadores informais' nas escolas, alguns chegaram a afirmar que "não se formaram para trocar fraldas", por exemplo. Isso cria algumas dificuldades adicionais para a contratação, pela Semed, de pessoal devidamente qualificado para o ofício de professor auxiliar.

Ainda de acordo com a gestora, o segundo problema se refere à forma como as professoras de cada classe têm reagido e mesmo se comportado quanto à presença do(da) professor(a) auxiliar em salas de aula, haja vista que algumas jogam toda a responsabilidade do ensino a alunos(as)com deficiência para o(a) professor(a) auxiliar. Ou seja, sentem-se 'desobrigadas' a ensinar os(as) alunos(as) com deficiência, pensando que esse papel fica atribuído ao(à) professor(a) auxiliar, que muitas vezes atua em um contexto de relações de trabalho que "inferiorizam a sua função [na sala de aula] e o tornam subalterno no contexto escolar, traduzindo sua participação como excludente no conjunto das relações educacionais/políticas e escolares" (Machado 2017:138). A gestora destacou também que as demandas por professor auxiliar são erradas e comumente acompanhadas e balizadas por laudos médicos que, por sua vez, podem influenciar de forma equivocada as sentenças de juízes. Para ela, tem que analisar cada caso, contemplando os pedidos inclusive de acordo com o tipo de deficiência. Comentou que muitas pessoas com síndrome de Down na verdade nem precisam de professor auxiliar. Citou as pessoas com paralisia cerebral e as com autismo como potencial clientela que necessita de professor auxiliar, devido a suas necessidades de cuidados básicos de higiene, alimentação e locomoção (levar alimentos à boca, levar ao banheiro, trocar fraldas, etc.) e de 'controle de surtos' (este no caso das crianças com autismo).

Este relato etnográfico sintetiza a polarização quanto à demanda desse profissional, tendo como balizador a tensão entre a perspectiva técnico-pedagógica e a familiar, a polissemia da questão do cuidado e algo que é muito comum na educação infantil, mas que no ensino fundamental aparece de outra forma, que é a tensão entre educar e 
cuidar, o que revela um campo de reflexões que podem contribuir muito para o avanço dos estudos sobre deficiência na educação (Valle \& Connor 2014). Outra questão é que há, evidentemente, uma questão econômica e institucional por trás das decisões da Semed. Que critérios técnicos são usados para a decisão que afirma ser de natureza pedagógica? O 'segundo professor' (Machado 2017) parece representar um custo a mais e, por isso, haverá resistência administrativa.

Outra coisa é a questão do professor auxiliar ser usado para 'conter surtos', o que nos lembra da tendência dessa secretaria municipal de ensino de selecionar homens para serem professores auxiliares de crianças com autismo, pois assim poderiam 'contê-las' e aí a questão do cuidado se torna mais complexa, entrando também no campo da 'violência'. Esse cenário revela a possibilidade de uma 'inversão de dependência', quando a pessoa com deficiência cuidada passa a exercer poder frente ao(à) cuidador(a), o que é corroborado por Stacy Simplican (2015) ao demonstrar, em contraposição ao argumento da 'extrema dependência' de Kittay (1999), que cuidadores(as) também podem experienciar situações de vulnerabilidade em um contexto de relações de cuidado marcado pela "dependência complexa" entre quem é cuidado e quem cuida.

\section{O cuidado como violência}

Em Londres, Inglaterra, abril de 2014, a sul-africana Tania Clarence, 42 anos, sufocou até a morte, além de sua filha, Olivia, então com 4 anos, também seus filhos gêmeos, Ben e Max, 3 anos, enquanto o marido, Gary, 43 anos, viajava à África do Sul com a outra filha mais velha do casal, então com 8 anos. As notícias pela imprensa davam a entender que as três crianças "sofriam de atrofia muscular espinhal, uma doença progressiva que pode causar problemas respiratórios fatais", sendo a mais velha "a única a não nascer com problemas". Nas palavras do promotor público à época, "ela fez o que fez para acabar com o seu sofrimento". Não havia a possibilidade de "ver nenhuma outra alternativa", a não ser matar "para sair desse sofrimento." 
O episódio é revelador de um regime moral imbricado nas relações de gênero em torno da tarefa do cuidado: a mãe assume o ônus do cuidado na ausência do pai. A deficiência é percebida como sofrimento e está marcada por um contexto de stress incessante advindo da sobrecarga mental e esgotamento físico gerados pelo trabalho do cuidado, a ponto de, no limite, ter o poder da vida e da morte. Nesse sentido, há aqui uma imbricação entre cuidado e 'violência', quando o stress do(da) cuidador(a) se transforma em 'violência'. Para Raquel Guimarães,

"O cuidado como prática para satisfazer necessidades de outros pode se configurar como relações de desigualdade ou de autoridade, especialmente quando não houver autonomia da pessoa que está sendo cuidada. Muitas vezes, as necessidades dessa pessoa são definidas pela cuidadora, o que pode gerar relações opressivas. A prática do cuidado em relações de intensa dependência pode desconsiderar a singularidade da pessoa deficiente e projetar necessidades da cuidadora na pessoa cuidada" (Guimarães 2010:207-208).

Assim, uma pessoa com deficiência em situação de intensa dependência, sem apoio e/ou sem condições financeiras dificilmente consegue o acordo das "relações bem ajustadas" (Zelizer 2012:20) com sua família para o provimento de cuidado Por isso na maioria das vezes ela vive situações de 'violência' dentro de casa, como vemos no depoimento de Luana, 40 anos, de origem branca, negra e indígena, mulher com deficiência física em decorrência de esclerose múltipla, oriunda de um bairro de periferia em Belo Horizonte:

"Eu não tenho ninguém para cuidar de mim, eu me cuido sozinha.

E eu tenho dificuldades inúmeras, pois eu não consigo limpar a minha casa, fazer comida, não consigo passar roupa, arrumar a minha cama, com dificuldades eu faço a minha higiene pessoal, e troco as minhas roupas pessoais. [...]'Em 2008 quando terminou o tratamento da quimioterapia e quando houve uma briga da minha filha com meu pai... Que o meu pai me jogou no chão. Eu pedi uma medida protetiva pela Lei Maria da Penha, e consegui a medida protetiva. Só que o meu pai para fugir da culpabilidade criminal se aliou ao meu ex-marido advogado para que fosse defendê-lo [na justiça], quebrando a protetiva” (Luana). 
A história de Luana está balizada por um laudo pericial, assinado por uma assistente social, em que mostra a "situação precária/lastimável referente à higiene e falta de alimentos", além de possuir intensa dependência para realizar tarefas simples e rotineiras como trocar de roupa, tomar banho, cozinhar, limpar a casa e comprar comida, atividades essas que ninguém de sua família se dispõe a ajudá-la. Desse modo, sua história é atravessada por uma 'violência totalizante', no sentido de que envolve práticas de violência nas três esferas ou domínios estudados por Debert \& Oliveira (2009): privados, semipúblicos e públicos, com a participação de familiares (o pai idoso de 80 anos, o ex-marido, o filho e a filha), de psiquiatras e agentes estatais do sistema judiciário, em uma lista de violações previamente caracterizadas no documento sobre violências contra mulheres com deficiência da International Network of Women with Disabilities (INWWD 2010), que vão desde o abandono físico, a negação das necessidades de cuidado, o isolamento forçado e o confinamento dentro de sua casa sem acessibilidade, as internações involuntárias em hospital psiquiátrico, com aplicação constante e coercitiva de drogas psicotrópicas, as tentativas de controle e apropriação indébita de sua aposentadoria por parte de familiares, até a criação de pretextos para justificar a necessidade de interdição e privação da capacidade legal. Na ocasião Luana esclareceu que "no momento a esclerose múltipla está estacionada", porém há questionamentos médicos quanto ao diagnóstico anterior de "esclerose múltipla progressiva", uma vez que conseguiu recuperar um pouco as forças, o peso e não utiliza mais fraldas para adultos como acontecia antes. Desse modo, pôde recuperar a autonomia e a capacidade de agir para buscar seus direitos. A dimensão de classe é outro componente social que merece destaque. Segundo Luana, ela gasta a maior parte de sua aposentadoria de $\mathrm{R} \$ 1.200,00$ com remédios caros, plano de saúde e táxi, não sobrando mais nada para as demais necessidades, incluindo aí serviços de provedores de cuidado.

Já Karina, 47 anos, classe média, branca, mulher com deficiência física, com síndrome de Guillain-Barré desde a infância, sofreu assé- 
dio sexual de um médico ginecologista durante uma consulta médica de rotina:

"Ele começou a ficar de gracinha comigo né? [...] Ficar assim, muito risonho muito risonho, muito assim aquela coisa de querer né, é muita aproximação né. E eu muito nova [...]. Aí eu ia fazer periodicamente os meus preventivos [...]. [...] uma vez eu fui lá, deitei na maca, na maca né, aí estou naquela posição absolutamente desconfortável. Aí quando, sem roupa, só com o avental em cima da parte da barriga para baixo. Ele chegou [e] tirou, tirou o pano de cima, pegou na minha parte pubiana, aperto com a mão assim: 'Vamos ver essa coisinha linda aqui como é que ela está'. Eu fiquei azul, eu fiquei roxa. Eu fiquei, falei: Pronto, agora estou ferrada! Esse homem pode fazer qualquer coisa comigo. Porque eu com deficiência, eu não tenho como sair correndo daqui".

Outro momento da violência institucional foi praticada por uma médica ginecologista quando precisou proceder aos exames de mamografia e de controle do DIU11, tendo sido destratada por causa da aparência de seu corpo, bem como pelo 'trabalho pesado' de cuidado que daria à equipe:

"Eu lembro de uma situação na qual eu [...] fui fazer o meu preventivo, isso foi o ano passado. Então era para fazer o preventivo, o controle do DIU que eu uso e a mamografia, aí o meu médico falou assim 'Faça no tal do hospital', é um hospital de nome aqui, né, um hospital [que] atende [via] convênio particular, [...]aqui perto de casa. Falou [que] lá o pessoal tem uma equipe que te atende não sei o quê, falei okay. É bom que eu faça exames todos em um lugar só. Aí eu fui, marquei os dois num dia só, passei todas as raivas num dia só. Então quer dizer, o que eu queria resolver num dia só, todas as raivas do mundo eu passei naquele dia. [...] Primeiro fui fazer a ultrassonografia endovaginal para controle do DIU. Aí cheguei lá, primeiro a mulher me olhou assustada né, eu falei assim 'Bom, bom, que será que ela está pensando?...'. Aí eu entreguei a guia do que o médico estava recomendando para controle do DIU não sei o quê. [...] Antes de deitar na cama, ela [a médica ginecologista] falou assim: "Você devia ter falado que você tem deficiência porque tem uma cama de exame ginecológico que é mais fácil fazer esse exame, [...] então a gente pode descer lá'. E eu respondi: 'Então a gente desce no outro andar e faz, eu deito na cama e a senhora faz'. 'Ah mas agora não dá não, tem que ser feito com antecedência'. [...] Aí tinha 
uma cama normal reta, [...] ela falou assim: 'Você sobe na cama'. Falei assim 'Não subo na cama não, [...] tem que chamar gente para me ajudar.' Ela falou assim: 'Eu não posso te pegar no colo. Médico não pode pegar a gente no colo não, você sabe".

Esses relatos demonstram como as atitudes negativas em relação à deficiência refletem na vida cotidiana das mulheres com deficiência, quando necessitam realizar os mesmos exames preventivos recomendados às mulheres em geral, o que denota o desconhecimento e a falta de capacitação da equipe médica e de enfermagem quanto aos procedimentos de cuidado para com mulheres com deficiência física.

Karina e Luana ainda trouxeram vários outros relatos de situações de violência, ora envolvendo a participação de familiares responsáveis pelo seu cuidado, ora praticadas por profissionais das áreas de saúde ligadas ao cuidado, no sentido de que os conflitos, as agressões, as infrações durante o exercício profissional e demais abusos ocorreram sempre em um contexto permeado por relações de poder em torno da tarefa do cuidado. São relatos que evidenciam que, contrariamente ao apontado em publicações feministas sobre violências de gênero contra a mulher no âmbito conjugal, em que a dependência financeira e emocional são os principais motivos pelos quais as mulheres desistem de denunciar seus agressores, a maioria homens, nas violências contra mulheres com deficiência a questão da independência financeira fica em segundo plano, pois a primeira pergunta que emerge é: "Quem vai cuidar de mim?". Essa 'rede de cuidados' geralmente inclui pessoas de sua rede de parentesco, mas também pode envolver a participação de profissionais da saúde, revelando que as violências contra essas mulheres com deficiência se aproxima mais dos referenciais teóricos sobre as violências contra o sujeito político idoso do que o sujeito político mulher. Essa aproximação faz sentido porque pessoas com deficiência e pessoas idosas ambas performam o contorno dos corpos com impedimentos que necessitam do cuidado para desenvolver, potencializar ou manter suas capacidades básicas. É por isso que para muitas pessoas com deficiência e pessoas idosas é importante terem por perto 
a família para ter a rede de cuidado funcionando e continuar (sobre) vivendo até o fim de sua vida.

\section{Pensar a partir do cuidado}

Trazer estas três situações em que práticas que se pretendem 'de cuidado’ podem acarretar situações de infantilização, violência ou segregação para começar uma reflexão a partir do cuidado pode parecer contraditório. De fato, as situações em que relações de cuidado se dão como são, bem como os atores sociais que delas participam, devem a todo momento desenvolver estratégias para habitar esses contraditórios. Nosso argumento, no entanto, é justamente mostrar que a falta de um vocabulário próprio para falar destas relações de dependência e cuidado, muitas vezes tão complexas, é o que pode acabar em situações de desigualdade ou opressão.

Os modos de perceber e agir sobre a deficiência coexistem nas diferentes instituições que lidam com esta questão em seu cotidiano. É inegável a importância de ativistas e acadêmicos(as) deficientes na formulação e consolidação teórica daquilo que ficou conhecido como o 'modelo social da deficiência' (Diniz 2003 e 2007; Mello \& Nuernberg 2012) em romper com a hegemonia biomédica, para que a deficiência deixasse de ser encarada como uma tragédia individual cuja única alternativa seria a cura ou a reabilitação. Para os teóricos deste modelo o que impede a participação plena e produtiva das pessoas com deficiência na sociedade são as barreiras sociais impostas por um mundo não preparado para lidar com a diversidade corporal. Contudo, é importante ter em mente que estes teóricos que destacavam a autonomia e independência enquanto ideais a serem almejados por todos eram, em sua maioria, homens com impedimentos físicos, brancos e com alto grau de escolaridade (Diniz 2003 e 2007; Mello \& Nuernberg 2012).

Conforme dito, na década de 1980 teóricas feministas do cuidado chamaram a atenção para o modo como a discussão vinha sendo pautada por esses teóricos, por não desafiarem o pressuposto de uma 'mente-apta' (ablemindedness) e ignorarem todos aqueles cujas especifi- 
cidades corpóreas e mentais jamais alcançariam a independência, mesmo que fosse possível remover todas as barreiras sociais. Para a crítica feminista, esse ideal de independência e autonomia está fortemente baseado em pressupostos de racionalidade e individualidade. Por isso, pesquisadoras feministas como Eva Kittay e Joan Tronto apontaram para a importância de se discutir a subjetividade, refletindo sobre a experiência do cuidado, da dor e do sofrimento de habitar um corpo deficiente. Ao invisibilizarem esses aspectos, incorrem no equívoco de ignorar não apenas as realidades daquelas pessoas com deficiência para quem a independência não será possível, mas também daquelas que lhes provem o cuidado.

É nesta intersecção entre a reivindicação por autonomia e independência e a necessidade de uma rede de cuidados que nossa discussão está situada. No Brasil boa parte do discurso dominante sobre as pessoas com deficiência é aquele mobilizado pela fantasia solidarista da compaixão e caridade, levando, muitas vezes, à segregação social por meio da institucionalização ou do confinamento em serviços reservados somente para este público, sem maiores preocupações com a participação política ou social. No entanto, as lutas dos movimentos sociais e também de abordagens teóricas sobre a questão, fizeram com que se difundisse o regime da autonomia e busca de direitos, sob o paradigma da cidadania (Santos 2008; Borges 2018). Assim como ocorreu em países europeus e da América do Norte, também no Brasil a ideia de cidadania está presente e é fortemente pautada pelo direito de escolha, de autoafirmação e de responsabilização individual (Pols, Althoff \& Bransen 2017).

Como aponta a antropóloga Annemarie Mol (2008), a chamada 'lógica da escolha', individual, racional e liberal, considerada basilar para o Ocidente, não dá conta das situações aqui apresentadas. Segundo a autora, na lógica ocidental a autonomia, o direto individual de escolher e a responsabilização pelas decisões tomadas são centrais e indisponíveis. Essa perspectiva está baseada em pressupostos de liberdade em que a escolha é sempre apresentada como individual, apagan- 
do todas as redes de relações e as situações onde as escolhas são feitas. Nesse sentido, defende que as práticas devem ser compreendidas a partir de uma 'lógica do cuidado', em que quem recebe o cuidado não seja tido como sujeito passivo, mas sim enquanto pessoas que estão constantemente fazendo algo dentro dessas relações. Assim, a lógica do cuidado "não está preocupada com nossa vontade, e com o que podemos escolher, mas se concentra no que nós fazemos. [...] A pergunta crucial não é o quão ativos nós somos, mas em que tipos de atividades nos engajamos" (Mol 2008b:7).

Não se trata, pois, de ignorar a importância de se reconhecer a voz das pessoas com deficiência e a necessidade de que seus direitos sejam respeitados. Pensar essas relações a partir de uma lógica do cuidado permite, ao contrário, reconhecermos o papel ativo que todas as partes das relações exercem nessas práticas. É necessário que não se presuma o tipo de cuidado mais adequado a partir de preceitos gerais, mas sim que ele seja uma co-construção cotidiana. $O$ cuidado não pode ser compreendido como algo estabilizado. Ao contrário, ele é um processo aberto, composto por interações e intervenções contínuas que visam o bem-estar daquele que o recebe, bem-estar que tampouco é estabelecido de antemão ( $M o l 2008 b)$, porquanto se constitui na prática, no decurso dessas relações. Daí deriva a necessidade de também pensar a deficiência a partir do cuidado, afinal, conforme se depreende das narrativas aqui apresentadas, presumir a vulnerabilidade das pessoas com deficiência e não incluílas enquanto parte ativa das relações de cuidado, está intrinsecamente ligado a situações de abuso ou distorções que venham a ocorrer. A invisibilização das relações de dependência potencializa os abusos cometidos em relações de cuidado, uma vez que cuidado e dependência são as duas faces da mesma moeda (Kittay 1999).

Evidente que nessas relações há desigualdades de vulnerabilidades ou condições que as tornam relações onde há desigualdade de poder. Entretanto, conforme destaca Kittay (1999), tal desigualdade não deveria levar à opressão ou submissão de uma parte a outra. Nesse 
sentido, as relações de dependência seriam 'relações morais paradigmáticas' que, para não se tornarem relações de dominação, necessitam do trabalho do cuidado. A dominação, a opressão, a infantilização advêm não das práticas de cuidado, mas do fato dessas práticas se darem em um mundo onde a escolha é tida como o valor central e onde aquele que está na posição de receber o cuidado será sempre apresentado como submisso. Ou, em última instância, como menos pessoa (Kittay 2011). Uma ética baseada nos ideais de autonomia e independência é corponormativa porque segrega corpos que não se enquadram nos padrões de referência pré-estabelecidos pelo sistema capitalista ocidental. Reconhecer a dependência como constituinte da condição humana e desestigmatizar a necessidade de cuidado deve ser crucial para garantir o bem-estar e a dignidade das pessoas com deficiência e seus(suas) cuidadores(as).

\section{Considerações Finais}

Ao apresentarmos essas três aproximações, as quais são inclusive contraditórias em si, buscamos apontar a polissemia do termo cuidado, que acaba sendo utilizado de modo tão plural, com conotações e denotações tão distintas. No entanto, pensar a deficiência a partir de uma ética de cuidado, ou melhor, das relações e práticas de cuidado que a conformam e que são por ela conformadas, significa atentar-se justamente para as associações mais invisibilizadas dessas redes e trazer à tona atores sociais que são muitas vezes desconsiderados tanto por pesquisadores(as) quanto por ativistas (Puig de la Bellacasa 2011). Ao fazermos isso, acreditamos que evitamos agir como mais um agente moralizador na trajetória desses sujeitos, e contribuímos para pensar criticamente sobre quais vozes e corpos são sistematicamente silenciados nessas relações de cuidado e dependência, as quais não deixam de ser relações de poder entre desiguais, o que não significa que devam ser transformadas em relações de dominação ou subjugação.

Nesse sentido, para Eva Kittay (2007) o cuidado deve levar ao outro o bem-estar, deixá-lo melhor do que antes daquela relação esta- 
belecer-se. Para tanto, não basta uma intenção de cuidado, mas sim o efeito que essas práticas produzem. Pensando que o self da ética do cuidado é sempre um self-em-relação e dependente, "nosso próprio sentido de bem-estar está conectado ao cuidado adequado e ao bem -estar do outro." (Kittay 2007:5). Com isso, o ato de cuidar passa a ser a realização desse conceito de self, em que a ética do cuidado não se refere a sujeitos que são iguais, mas sim daqueles que são "desiguais em idade, capacidades, e/ou poder" (Kittay 2007:5). Dessa maneira, as "relações de responsabilidades e relações de confiança àqueles que necessitam de nosso cuidado ou assistência são destacadas" (Kittay 2004:4) e os danos e as violências se dão quando essas relações são quebradas ou fracassam.

As experiências etnográficas trazidas aqui também apontam para outro fator que não pode ser desconsiderado: nem sempre é possível identificar o que este 'bem-estar' é. Por isso, propomos ser interessante pensar as práticas de cuidado como aquilo que Mol apresenta como um tinkering ${ }^{10}$, uma vez que 'bons' diferentes coexistem e refletem diferentes valores e também diferentes modos de ordenar a realidade, devendo ser tratados em conjunto e coordenados em cada situação, a fim de se encontrar a solução que se apresentar como a mais adequada naquele momento. $\mathrm{O}$ ato de cuidar seria, portanto, esse conjunto de práticas de tinkering. $\mathrm{O}$ cuidado não pode ser tomado como uma solução definitiva e absoluta para determinada situação, mas sim como um processo contínuo, uma grande experimentação que se dá de forma atenta e preocupada com as diferentes necessidades apresentadas naquele espaço e tempo específicos.

Ainda, os casos mencionados trazem tensões sempre presentes nessas práticas de tinkering. Desde a sempre linha tênue entre o ato de cuidar e a superproteção, até aqueles casos extremos que levam a atos de violência física, agressão e mesmo a morte. Vale destacar, também, o quanto a sobreposição de atores sociais, desejos, bens a serem protegidos e versões de bem-estar tornam complexa a tarefa cotidiana de cuidar e, principalmente, de ser cuidado. Não por acaso, relações 
de dependência tornam-se tão comumente relações de subjugação e opressão. Uma realidade que é exarcebada ao pensar o trabalho do cuidado enquanto algo instrumental, característica da percepção de que "a independência tem a ver com controle e tomada de decisões e nada a ver com a necessidade de necessitar de assistência para as tarefas básicas do dia-a-dia" (Kittay 2007:4). Por isso, desestigmatizar a dependência é parte central do argumento de Eva Kittay.

Trazer o cuidado para o centro da preocupação etnográfica remete a corpos que serão cuidados e corpos que cuidam. Porém, essa materialidade não é definida de antemão, porque o social e o material influenciam-se mutuamente e podem ser pensados enquanto coproduzidos. As performances que conformam o bom e o mau cuidado nos permitem ver as múltiplas possibilidades de associações entre pessoas e entre pessoas e instituições, e os múltiplos agenciamentos e modos de se relacionar com a família, a comunidade e o Estado. Além disso, estamos diante de uma lógica cujo fracasso e fragilidade não só são aceitos, mas são parte do projeto (Mol 2008b). São os diferentes 'bons' que sustentam as relações de cuidado e são as suas diferentes versões que fazem com que as práticas de cuidado sejam permeadas por tensões e negociações entre indivíduos.

\section{Notas}

* As autoras agradecem à Capes pela concessão de bolsas de pesquisa. A segunda autora agradece ao CNPq pelo financiamento do projeto 'Teoria Feminista, Teoria Queer ou Teorias Sociais Contemporâneas? O campo dos estudos de gênero e sexualidade no Brasil'.

1 Poder-se-ia estendê-la também para não humanos (Cf. Nussbaum 2007).

2 Considerando que há um 'contínuo do cuidado' que fundamenta o funcionamento de sociedades alicerçadas em relações de interdependência, é interessante também perceber o cuidado como um fato social total nos termos de Marcel Mauss (2003).

3 Para as feministas, no entanto, autonomia seria 'escolha', expressa na máxima feminista 'Meu corpo, minhas regras!'. Assim, na teoria feminista, a autonomia seria justamente a faculdade de tomar as próprias decisões, enquanto a independência 
estaria ligada ao 'controle do corpo' para fazer ou realizar tarefas sem auxílio ou suporte. Em nossa experiência de campo, no entanto, os termos são utilizados de modo bastante diverso, por vezes se aproximando desta distinção; outras vezes, da concepção dos ativistas com deficiência. Há, ainda, situações em que autonomia e independência se confundem pelo senso comum, ao tratar ambas como se fossem quase sinônimos.

4 Por se tratar de trabalhos de campo realizados individualmente e em diálogo com os temas de nossas pesquisas, em alguns momentos do texto optamos pelo uso da terceira pessoa do singular.

5 Usamos 'deficiência cognitiva' no sentido de 'deficiência intelectual', diferenciando-a de 'deficiência mental' como sinônimo de 'deficiência psicossocial', esta última referente às pessoas com as 'sequelas de transtorno mental', de acordo com a Lei no 10.216/2001. Porém, segundo a Convenção sobre os Direitos das Pessoas com Deficiência (Brasil, 2008), as pessoas com sofrimento mental também são consideradas pessoas com deficiência, sob a tipificação de 'deficiência mental', para diferenciá-la de deficiência intelectual, esta última alusiva a uma parte específica do funcionamento do intelecto, e não de toda a mente. Além disto, optamos por utilizar o termo 'deficiência cognitiva' por entender, assim como colocam Eva Kittay \& Licia Carlson, ser ela mais abrangente do que a primeira e porque "algumas formas de deficiência cognitiva não implicam a diminuição da capacidade intelectual” (2010:1).

6 Para preservar a identidade dos(das) interlocutores(as), adotamos nomes fictícios.

7 Disponível em: <http://educacao.uol.com.br/noticias/2014/05/06/justica-decide-que -aluna-com-sindrome-de-down-deve-ter-professor-exclusivo.htm>. Acesso em: 10 nov. 2018.

8 Adaptação razoável significa "as modificações e os ajustes necessários e adequados que não acarretem ônus desproporcional ou indevido, quando requeridos em cada caso, a fim de assegurar que as pessoas com deficiência possam gozar ou exercer, em igualdade de oportunidades com as demais pessoas, todos os direitos humanos e liberdades fundamentais." (Brasil 2008:s/p).

9 Ver, por exemplo, a matéria 'Mulher admite ter sufocado três filhos deficientes e não deve responder por homicídio doloso', disponível em: <https://oglobo.globo. $\mathrm{com} / \mathrm{mundo} / \mathrm{mulher}$-admite-ter-sufocado-tres-filhos-deficientes-nao-deve-responder -por-homicidio-doloso-14231422>.

10 termo tinkering é de difícil tradução em razão das diferentes acepções que a palavra em inglês possui. Por essa razão, optamos por manter o termo em inglês. Segundo o dicionário Merriam-Webster o verbo to tinker pode ser definido como: "to work in the manner of a tinker; especially: to repair, adjust, or work with something in an unskilled or experimental manner". Algumas traduções possíveis seriam a de ajustar, reparar ou brincar com algo a fim de dar-lhe nova forma.

\section{Referências}

BORGES, Jorge. 2018. Política da Pessoa com Deficiência no Brasil: percorrendo o labirinto. Tese de Doutorado. Porto Alegre: UFRGS. 
BRASIL. 2008. "Decreto Legislativo no 186, de 9 de julho de 2008. Aprova o texto da Convenção sobre os Direitos das Pessoas com Deficiência e de seu Protocolo Facultativo, assinados em Nova York, em 30 de março de 2007”. Diário Oficial da União, Brasília-DF, 10 jul. 2008, seção 1, edição 131, p. 1. (http://www2. senado.leg.br/bdsf/handle/id/99423; acesso em 10/12/2018).

DEBERT, G. \& OLIVEIRA, A. 2009. "O idoso, as delegacias de polícia e os usos da violência doméstica." In MORAES, A. \& SORJ, B. (eds.): Gênero, violência e direitos na sociedade brasileira, pp. 23-48. Rio de Janeiro: 7Letras.

DEBERT, G. \& PULHEZ, M. 2017. “Apresentação.” In DEBERT, G. \& PULHEZ, M. (eds): Desafios do Cuidado: gênero, velhice e deficiência, pp. 5-27. Campinas: Unicamp/IFCH (Textos Didáticos, 66).

DINIZ, Debora. 2003. "Modelo social da deficiência: a crítica feminista". Série Anis, 28:1-8. . 2007. O Que é Deficiência. São Paulo: Brasiliense.

FAUR, Eleonor. 2014. El cuidado infantil en el siglo XXI. Mujeres malabaristas en uma sociedad desigual. Buenos Aires: Siglo XXI Editors.

FIETZ, Helena M. 2016. Deficiência e Práticas de Cuidado: uma etnografia sobre 'problemas de cabeça' em um bairro popular. Dissertação de Mestrado. Porto Alegre: UFRGS.

FONSECA, C. \& FIETZ, H. 2018. "Collectives of Care in the Relations Surrounding People with 'head troubles': Family, Community and Gender in a WorkingClass Neighborhood of Southern Brazil.” Sociologia E⿱ Antropologia, 8(1):223-243.

GUIMARÃES, Raquel. 2010. "Gênero e Deficiência: um estudo sobre as relações de cuidado.” In DINIZ, D. \& SANTOS, W. (eds.): Deficiência e Discriminação, pp. 197-228. Brasília: Letras Livres.

HELD, Virginia. 1993. Feminist Morality: Transforming culture, society, and politics. Chicago/London: The University of Chicago Press.

HIRATA, H. \& GUIMARÃES, N. (eds.). 2012. Cuidado e Cuidadoras: As várias faces do trabalho do care. São Paulo: Atlas.

HUGHES, B. et al. 2017. "Trabalhos de amor perdidos? Feminismo, Movimento de Pessoas com Deficiência e Éticas do Cuidado.” In DEBERT, G. \& PULHEZ, M. (eds): Desafios do Cuidado: gênero, velhice e deficiência, pp. 101-124. Campinas: Unicamp/IFCH (Textos Didáticos, 66).

INWWD. 2010. Document on Violence against Women with Disabilities, [S.1.], 4 October 2010. Discussion Group on Violence. (http://wwda.org.au/wpcontent/uploads/2013/12/inwwdviol2010.pdf; acesso em 12/11/2018).

KITTAY, Eva F. 1999. Love's Labor: Essays on Women, Equality and Dependency. New York: Routledge.

2007. "A Feminist Care Ethics, Dependency, and Disability." APA Newsletter on Feminism and Philosophy, 6(2): 3-7.

2010. "The Personal Is Philosophical Is Political: A Philosopher and Mother of a Cognitively Disabled Person Sends Notes from the Battlefield. In.: KITTAY, E. \& CARLSON, L. (eds.): Cognitive Disability and Its Challenge to Moral Philosophy, pp.393-413. Chisch 
KITTAY, Eva F. 2011. "The Ethics of Care, Dependence, and Disability." Ratio Juris, 24(1):49-58.

KITTAY, Eva F. \& CARLSON, Licia. 2010. "Introduction: Rethinking Philosophical Presumptions in Light of Cognitive Disability". In KITTAY, E. \& CARLSON, L. (eds.): Cognitive Disability and Its Challenge to Moral Philosophy, pp.1-25. Chischester: Wiley-Blackwell.

KRÖGER, Teppo. 2009. "Care Research and Disability Studies: Nothing in Common?" Critical Social Policy, 29(3):398-420.

MACHADO, Ana Paula. 2017. Investigando as significações produzidas por segundos professores sobre seu trabalho no contexto das práticas de educação especial na perspectiva da educação inclusiva. Dissertação de Mestrado. Florianópolis: UFSC.

MARTIN, D., SPINK, M. \& PEREIRA, P. 2018. "Corpos múltiplos, ontologias políticas e a lógica do cuidado: uma entrevista com Annemarie Mol.” Interface - comunicação, saúde, educação, 22(64):295-305.

MAUSS, Marcel. 2003. "Ensaio sobre a dádiva." In MAUSS, M.: Sociologia e Antropologia, pp. 183-314. Rio de Janeiro: Cosac \& Naify.

MELLO, Anahi G. 2010. "A Construção da Pessoa na Experiência da Deficiência: corpo, gênero, sexualidade, subjetividade e saúde mental.” In MALUF, S. \& TORNQUIST, C. (eds): Gênero, Saúde e Aflição: abordagens antropológicas, pp. 133-191. Florianópolis: Letras Contemporâneas.

MELlO, A. \& NUERNBERG, A. 2012. "Gênero e Deficiência: interseções e perspectivas." Revista Estudos Feministas, 20(3):635-655.

MOL, Annemarie. 2002. The Body Multiple: Ontology in medical practice. Durham/ London: Duke University Press.

.2008a. "Política Ontológica: algumas ideias e várias perguntas." In.: NUNES, João Arriscado \& ROQUE, Ricardo (Orgs.): Objectos Impuros: experiências em estudos sociais da ciência, pp. 63-77. Porto: Edições Afrontamento.

2008b. The Logic of Care: Health and the problem of patient choice. New York: Routhledge.

MOLINIER, Pascale. 2012. "Ética e trabalho do care." In HIRATA, H. \& GUIMARÃES, N. (eds.): Cuidado e Cuidadoras: as várias faces do trabalho do care, pp. 29-43. São Paulo: Atlas.

MORRIS, Jenny. 1997. "Care or Empowerment? A Disability Rights Perspective." Social Policy and Administration, 31(1):54-60.

2001. "Impairment and Disability: Constructing an Ethics of Care that Promotes Human Rights." Hypatia, 16(1):1-16.

POLS, J., ALTHOFF, B. \& BRANSEN, E. 2017. "The Limits of Autonomy: Ideals in Care for People with Intellectual Disabilities." Medical Anthropology, 36(8):772-785.

PUIG DE LA BELLACASA, Maria. 2011. "Matters of Care in Technoscience: Assembling Neglected Things". Social Studies of Science, 41(1):85-106. 
REINDAL, Solveig M. 1999. "Independence, Dependence, Interdependence: Some reflections on the subject and personal autonomy." Disability $\mathfrak{E}$ Society, 14(3):353-367.

RUDDICK, Sara. 1989. Maternal Thinking. New York: Beacon Press.

SANTOS, Wederson R. 2008. "Pessoas com Deficiência: nossa maior minoria." Physis: Revista de Saúde Coletiva, 18(3):501-519.

SIMPLICAN, Stacy C. 2015. "Care, Disability, and Violence: Theorizing Complex Dependency in Eva Kittay and Judith Butler." Hypatia, 30(1):217-233.

TRONTO, Joan C. 1993. Moral Boundaries: A political argument for an ethic of care. New York: Routledge.

VALLE, J. \& CONNOR, D. 2014. Ressignificando a deficiência: da abordagem social às práticas inclusivas na escola. Porto Alegre: AMGH.

ZELIZER, Viviana. 2012. "A economia do care". In HIRATA, H. \& GUIMARÃES, N. (eds.): Cuidado e Cuidadoras: as várias faces do trabalho do care, pp. 15-28. São Paulo: Atlas.

\begin{abstract}
Care is a key category in disability feminist theory. Yet, as an emic and also an analytical term, care has been an object of dispute among activists and scholars in the field of disabilities. Here, we aim to, first, trace the trajectory of the category in both the disability rights movement and the theories that support the social model of disability in order to identify conflicts that are inherent to this dialogue. Then, drawing on research conducted with mothers/caretakers of adults with cognitive disability and women with physical disabilities with a history of violence in the cities of Porto Alegre and Belo Horizonte, Brazil, respectively, as well as on secondary sources, we will problematize four parallels regularly faced by our interlocutors in their everyday lives: care as 'overprotection', care as 'to educate', and care as 'violence'. The goal is to reflect on the opposition commonly made between the concepts of 'care', 'autonomy', and 'independence'. With the support of feminist care theories, especially Eva Kittay's work, we will analyze care not only as a social and emotional practice and a moral category but also as an 'ethnographic entry' for our reflections on the way by which disability is co-produced in the everyday lives of our interlocutors. This will enable a better understanding of the experience of disability itself.
\end{abstract}

Keywords: Care, Disability, Autonomy, Independence.

Recebido em agosto de 2018. Aprovado em dezembro de 2018. 